\title{
A WET OXIDATION METHOD FOR AMS RADIOCARBON ANALYSIS OF DISSOLVED ORGANIC CARBON IN WATER
}

\author{
Alex Leonard ${ }^{1}$ Stephanie Castle $\mathrm{S}^{1,2}$ • G S Burr ${ }^{1,3}$ - Todd Lange ${ }^{1}$. Jim Thomas $^{4}$ \\ ABSTRACT. We present a method for the extraction of dissolved organic carbon (DOC) from water. The method is adapted \\ from Burr et al. (2001) using the basic steps: 1) sample filtration; 2) acidification to liberate and remove dissolved inorganic \\ carbon (DIC); 3) evaporation of the sample to isolate salts that include trace quantities of carbon; 4) combustion of the salts; \\ and 5) purification of the $\mathrm{CO}_{2}$. Two significant improvements have been made to the earlier method. The first is to use wet \\ oxidation with potassium permanganate to oxidize organics in place of the combustion step and the second is the development \\ of a reduction/oxidation purification procedure to remove sulfur and nitrogen oxides that may form during the oxidation step. \\ Wet oxidation has a practical advantage over the previous method because it proceeds at low temperature $\left(70^{\circ} \mathrm{C}\right)$. The orig- \\ inal method required quartz vessels to oxidize the salts at $900^{\circ} \mathrm{C}$. At this temperature, salts in the samples formed gases that \\ interfered with the isolation of $\mathrm{CO}_{2}$ and the quartz vessels degraded with each combustion, affecting their structural integrity. \\ The expensive quartz vessels could only be used for a limited number of samples, whereas Pyrex vessels used for wet oxida- \\ tion are inexpensive and can be used indefinitely.
}

The blank fraction modern carbon $(f)$ and its mass dependence for the refined technique was determined from repeat analyses of salicylic acid produced from petrochemicals. For samples with a mass $m$ above $0.5 \mathrm{mg}, F=0.0083 \pm 0.0011$. For samples below $0.5 \mathrm{mg}$, the blank follows a $1 / \mathrm{m}$ dependence as observed for other accelerator mass spectrometry (AMS) ${ }^{14} \mathrm{C}$ measurements (Donahue et al. 1990). The reproducibility of the method is demonstrated using repeat measurements from a variety of samples, including a sample measured with the former high-temperature $900^{\circ} \mathrm{C}$ combustion technique. The virtues of the wet oxidation method are that it is economical, produces a low blank, and provides good reproducibility.

\section{INTRODUCTION}

Measuring the radiocarbon content of dissolved organic carbon (DOC) in groundwater samples, along with dissolved inorganic carbon (DIC), is a proven geochemical tool for understanding the hydrodynamics of an aquifer system (Murphy et al. 1989; Hendry and Wassenaar 2005, 2011; Noseck et al. 2009) and has been applied to freshwater systems from a range of surface environments, including rivers (Raymond and Bauer 2001; Sickman et al. 2010), lakes (Nara et al. 2010a; Zigah et al. 2012), forested catchment areas (Schiff et al. 1997), peatlands (Chasar et al. 2000; Tipping et al. 2010), estuaries (Wang et al. 2007), rainwater (Avery et al. 2006), and sewage effluent (Nara et al. 2010b). A number of different methods can be used to liberate DOC from groundwater for accelerator mass spectrometry (AMS) ${ }^{14} \mathrm{C}$ analysis. Common methods include UV oxidation (Williams and Druffel 1987; Purdy et al. 1992: Raymond et al. 2004), solid phase extraction of various sorts (Murphy et al. 1989; Wassenaar et al. 1990; Sickman et al. 2010), combustion following evaporation and/or freeze-drying (Burr et al. 2001; Palmer et al. 2001; Neff et al. 2006), and ultrafiltration (Thomas 1996; Thomas et al. 1996; Benner et al. 2004). Each of these techniques has its advantages. The UV oxidation approach works especially well in seawater (Druffel et al. 1992; Bauer et al. 1998) where the relatively large proportion of dissolved salts poses a problem for the other techniques. The solid phase extraction and ultrafiltration methods have the virtue that they can be used to distinguish between different classes of organic molecules, according to their molecular weights and chemical characteristics. The direct combustion approach is the simplest method and measures the total DOC in a sample. It requires a minimal sample size, features good reproducibility, and low analytical blanks.

\footnotetext{
${ }^{1}$ University of Arizona, Physics Dept., Tucson, Arizona 85721-0081, USA.

${ }^{2}$ Michigan State University, Dept. of Chemistry, East Lansing, Michigan 48824-132, USA.

${ }^{3}$ National Taiwan University, Dept. of Geosciences, Taipei, Taiwan. Corresponding author. Email: burr@u.arizona.edu.

${ }^{4}$ Desert Research Institute, 2215 Raggio Parkway, Reno, Nevada 89512, USA.
} 


\section{A Leonard et al.}

This study describes in detail the direct combustion technique that is used at the NSF-Arizona AMS Facility. The method is applicable to a wide range of samples, including groundwater samples as small as $500 \mathrm{~mL}$ with DOC concentrations as low as tens of $\mu \mathrm{g} / \mathrm{L}$ carbon. A primary goal of the study is to quantify the relationship between the magnitude of the blank and sample size. This is known to be significant for AMS samples that contain less than $500 \mu \mathrm{g}$ C (Donahue et al. 1990).

\section{METHODS}

For the blank measurements, the following wet oxidation method was employed: ${ }^{14} \mathrm{C}$-free salicylic acid was combined with $100 \mathrm{mg}$ granular potassium permanganate $\left(\mathrm{KMnO}_{4}\right)$ in 1 finger of a 2-fingered glass flask. To the other finger was added $10 \mathrm{~mL}$ of phosphoric acid (85\%). The flask was subsequently evacuated on a high-vacuum line and sealed via a valve fixed to the top of the flask. The evacuated sealed flask was then detached from the vacuum line and tipped at an angle in order to pour the phosphoric acid into the finger with the salicylic acid-potassium permanganate mixture. The sample was then heated to $70{ }^{\circ} \mathrm{C}$ on a heat block overnight (minimum of $10 \mathrm{hr}$ ). When the reaction was completed, the sample flask was fixed to a high-vacuum line, and the $\mathrm{CO}_{2}$ gas produced from the reaction was allowed to bleed through 2 isopropanol-dry ice traps and 1 liquid nitrogen trap. To minimize isotopic fractionation of the gas, the pressure in the cold trap was maintained below $10^{-1}$ Torr while bleeding. Once the vacuum in the line reached $10^{-5}$ Torr or better, the sample was isolated using another liquid nitrogen cold trap, then subsequently expanded into a known, measured volume in order to calculate the volume of $\mathrm{CO}_{2}$. The sample was then collected in a sample vessel and submitted for ${ }^{13} \mathrm{C}$ and ${ }^{14} \mathrm{C}$ analyses. Flask clean-up involved rinsing with hot concentrated $\mathrm{HCl}$ followed by purified water.

This sample preparation method was replicated numerous times and the sample sizes covered a range from 20 to $500 \mu \mathrm{g}$. Additionally, standard samples were also tested, using oxalic acid I standard, with a theoretical yield of about $1 \mathrm{mg}$. Once the blank was established, the method was used to process groundwater samples. The samples were first filtered through a $0.7-\mu \mathrm{m}$ glass microfiber filter fixed to a 500-mL Nalgene container with a hand-operated vacuum pump. It is possible to utilize a $0.45-\mu \mathrm{m}$ nylon filter if proper washing techniques are employed to remove contaminants; however, for the purposes of this study and avoidance of carbon contamination, the $0.7-\mu \mathrm{m}$ glass microfiber filter was chosen. The filtered sample, $\sim 1.0 \mathrm{~L}$, was then transferred to a large, round-bottomed flask and $20 \mathrm{~mL}$ of phosphoric acid (85\%) was introduced into the flask. The vessel was then fixed to an evaporation system (Figure 1) and heated to $40^{\circ} \mathrm{C}$ while under a vacuum of $10^{-2}$ Torr. The temperature was maintained at $40{ }^{\circ} \mathrm{C}$ to avoid losing volatile organic compounds. During this heating period, the water evaporated from the sample was frozen in an isopropanol-dry ice trap, cooled with a chiller unit (Figure 1), and the dissolved organic carbon was left behind, along with dissolved salts suspended in the phosphoric acid. The evaporation step took up to 3 days to complete.

After the sample was evaporated, the reaction flask was chilled in an ice bath, brought up to atmosphere, and $150 \mathrm{mg}$ of potassium permanganate was added to the flask. The sample-phosphoric acid mixture in the flask is very hygroscopic and an inert gas (e.g. $\mathrm{N}_{2}$ or Ar) should be used to bring the pressure in the vessel up to atmosphere, before adding the potassium permanganate. Following this step, the flask was pumped down to $10^{-2}$ Torr and isolated from the vacuum system. The sample flask was then heated to $70{ }^{\circ} \mathrm{C}$ overnight to allow the reaction to proceed. Next, the flask was attached to a high-vacuum line and the $\mathrm{CO}_{2}$ gas produced from the reaction was bled through 2 isopropanol-dry ice traps and 1 liquid nitrogen trap (Figure 2). A modification adopted during the development of this procedure was to place the sample vessel in a large isopropanol-dry ice bath, to

provide an additional water trap. As in the earlier procedure, the $\mathrm{CO}_{2}$ is passed through 2 additional cold traps and collected as a solid in a liquid nitrogen cold trap. The $\mathrm{CO}_{2}$ is then allowed to subli- 
Wet Oxidation Method for AMS ${ }^{14} \mathrm{C}$ Analysis of DOC

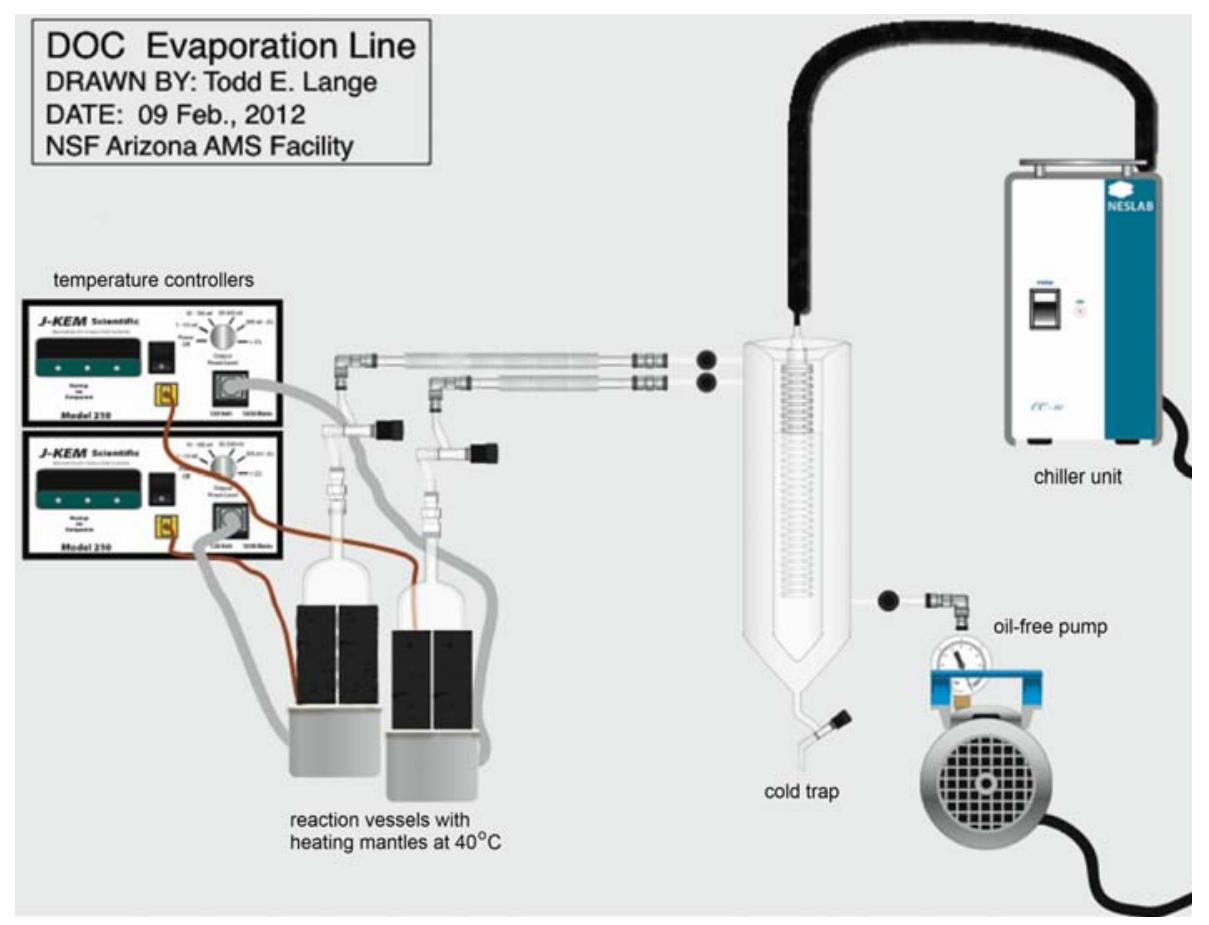

Figure 1 DOC evaporation and reaction vacuum line. This line can accommodate 2 samples at the same time.

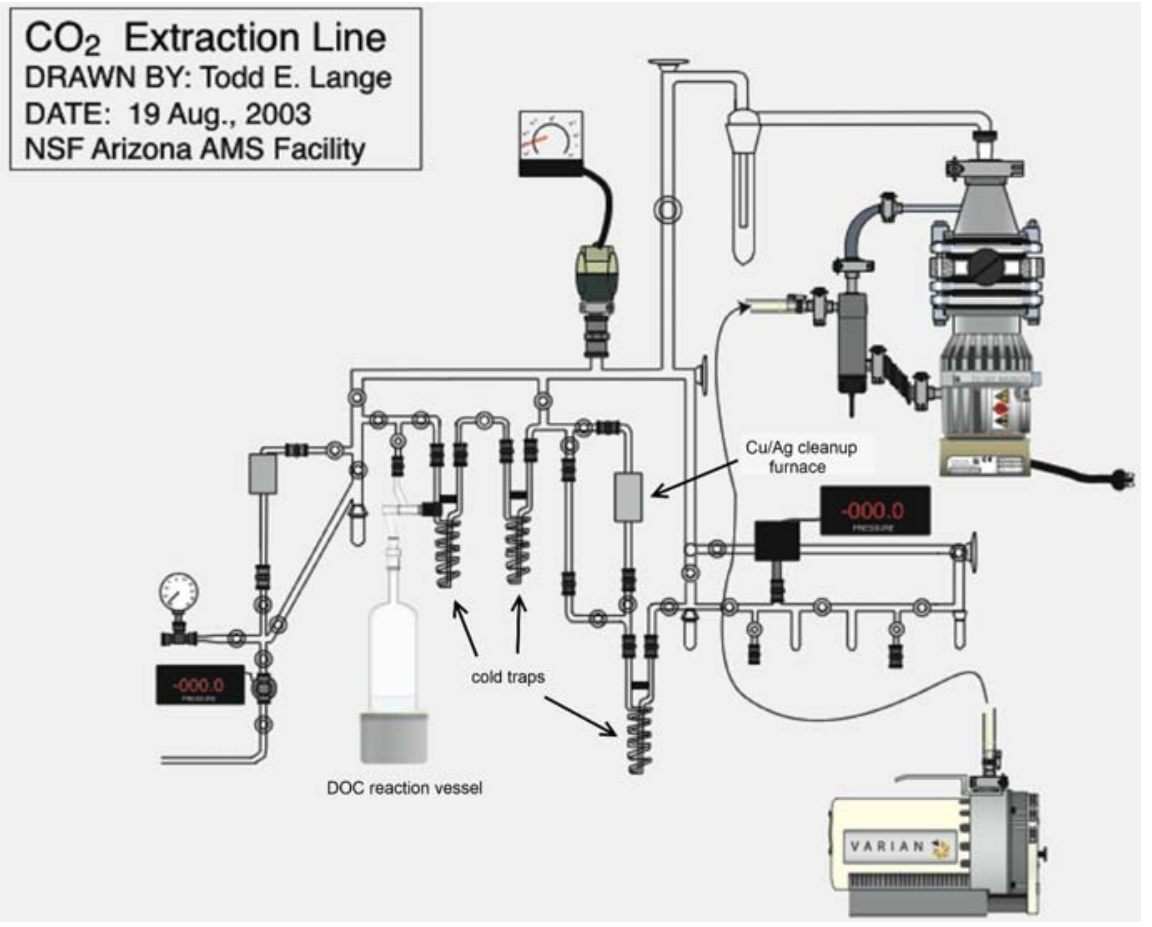

Figure 2 DOC - $\mathrm{CO}_{2}$ collection and purification vacuum line 


\section{A Leonard et al.}

mate and expand into an area of the vacuum line containing a copper/silver reduction furnace to purify it (Figure 2). Any reducible contaminate gases are removed once the pressure in the line has stabilized. The sample is then transferred into a known, measured volume section of the vacuum line in order to calculate the mass of $\mathrm{CO}_{2}$. Once collected in a sample vessel, the $\mathrm{CO}_{2}$ was then analyzed for $\delta^{13} \mathrm{C}$ using a conventional isotope ratio mass spectrometer and for ${ }^{14} \mathrm{C}$ by AMS. The sample flasks used in the above preparation method can be used repeatedly after cleaning.

\section{Gas Purification}

For high sulfur groundwater samples, a reduction oxidation clean-up method was utilized to remove $\mathrm{SO}_{2}$. This step was taken because $\mathrm{SO}_{2}$ can inhibit the formation of graphite during the reduction reaction. The presence of $\mathrm{SO}_{2}$, and possibly nitrogen oxides, are sometimes obvious from the behavior of the sample on the vacuum line. Symptoms include 1) very slow transfer rates as gas is moved from one cold trap to the next; 2) unstable pressure readings after the gas has been frozen into a cold trap; and 3) visible coloration in samples frozen in liquid nitrogen. We routinely confirm these observations with stable isotope measurements on a conventional mass spectrometer. Spectral traces of such samples typically show wide or irregular patterns instead of sharp peaks for each isotope. The method we developed produces sequential reduction/oxidation reactions in a single vessel. The idea is to reduce the $\mathrm{CO}_{2}$ and contaminating gases and then re-oxidize the $\mathrm{CO}_{2}$. From repeated experiments, we found that once reduced, the contaminating gases do not readily re-oxidize and are therefore removed. The technique uses $\mathrm{Zn}$ to reduce the gases and $\mathrm{CuO}$ to oxidize them. We are able to perform the reaction in a single tube because the reduction and oxidation steps occur at different temperatures, and the reduction temperature is significantly lower than the oxidation temperature. The clean-up procedure procedes as follows: 1) $\mathrm{CO}_{2}$ and contaminating gases are transferred to a quartz tube containing $10 \mathrm{mg}$ of $\mathrm{Zn}$ and $150 \mathrm{mg}$ of $\mathrm{CuO}$; 2) the sample is frozen in liquid nitrogen and any residual gas is pumped away as the tube is sealed off with a torch; 3 ) the tube is heated in an oven to $450{ }^{\circ} \mathrm{C}$ for $2 \mathrm{hr}$ to reduce the gases and then to $800{ }^{\circ} \mathrm{C}$ for $2 \mathrm{hr}$ to re-oxidize $\mathrm{CO}_{2}$. At this stage, the gas has been purified. After the tube has cooled, it is placed in a tube-cracker on the highvacuum line and the $\mathrm{CO}_{2}$ volume is measured. This method has worked for all freshwater samples that we have processed in the laboratory; however, when used on seawater the salt content was found to be too high to effectively remove the contaminating gases.

\section{RESULTS AND DISCUSSION}

The results of the AMS analyses are given in Table 1. These include results for salicylic acid blanks, oxalic acid standards, tap waters, and a groundwater sample analyzed using both the former method (oxidation at $900{ }^{\circ} \mathrm{C}$ ) and the current (wet oxidation) technique (measured $3 \mathrm{yr}$ apart). The repeat measurement on the groundwater sample agreed well with the original measurement (Table 1). By pooling the remaining repeat samples ( 3 oxalic acids and 3 tap waters), we calculate a reproducibility of $3 \%$, at a $1 \sigma$ confidence level.

The salicylic acid manufactured from petrochemicals was used to quantify our DOC blank and its mass dependence. The data are given in Table 1 and are plotted in Figure 3, as blank fraction modern carbon $(f)$ values. No mass correction or ${ }^{13} \mathrm{C}$ correction has been applied to these results, and only counting statistics are reported. Samples with very small masses $(<100 \mu \mathrm{g})$ show a sharp rise in $f$ as their carbon mass $(m)$ decreases. We also observe increased scatter in the results as we approach the sample size limit of the technique. This observed trend is consistent with a small but relatively constant amount of contaminant that is introduced into the sample during processing to graphite and is characteristic of AMS samples. That is, we can assign a $1 / m$ blank-mass relationship as $f(m)=f(1 \mathrm{mg}) / m \quad$ (Donahue et al. 1990) for samples $<500 \mu \mathrm{g}$. We estimate our DOC ground- 
Wet Oxidation Method for AMS ${ }^{14} C$ Analysis of DOC

water blank to be $f(1 \mathrm{mg})=0.0083 \pm 0.0011$. The red line in Figure 3 shows this value as it follows the $1 / m$ trend. When using this blank relationship, it is clear that the uncertainty of a measurement will increase as the mass of a sample decreases, for samples $<500 \mu \mathrm{g}$. In practice, this is quantified by expanding the error envelope for the very small samples, and propagating the blank error into the total uncertainty for a measurement.

Table 1 AMS ${ }^{14} \mathrm{C}$ results with $\pm 1 \sigma$ counting uncertainties. $f$ is the uncorrected fraction modern carbon (with no blank or ${ }^{13} \mathrm{C}$ correction) and $F$ is the fraction modern carbon (Donahue et al. 1990).

\begin{tabular}{|c|c|c|c|c|}
\hline Lab code & Lab \# & Mass (mg) & $\delta^{13} \mathrm{C}(\%)$ & $f$ \\
\hline \multicolumn{5}{|c|}{ Salicylic acid blanks } \\
\hline AA88186 & X19351 & 0.02 & -27.6 & $0.0624 \pm 0.0026$ \\
\hline AA88187 & X19352 & 0.04 & -27.5 & $0.0417 \pm 0.0016$ \\
\hline AA95763 & X21082 & 0.04 & -24.4 & $0.2580 \pm 0.0017$ \\
\hline AA95762 & X21081 & 0.05 & -23.7 & $0.2340 \pm 0.0017$ \\
\hline AA88190 & X19355 & 0.05 & -25.2 & $0.0887 \pm 0.0020$ \\
\hline AA88188 & X19353 & 0.07 & -25.2 & $0.0708 \pm 0.0013$ \\
\hline AA95765 & X21084 & 0.07 & -24.3 & $0.1434 \pm 0.0011$ \\
\hline AA93954 & X19474 & 0.08 & -24.8 & $0.0828 \pm 0.0015$ \\
\hline AA94705 & X20310 & 0.09 & -24.8 & $0.0854 \pm 0.0006$ \\
\hline AA95764 & X21083 & 0.09 & -25.1 & $0.1658 \pm 0.0011$ \\
\hline AA93950 & X19470 & 0.10 & -24.9 & $0.0585 \pm 0.0010$ \\
\hline AA95766 & X21085 & 0.10 & -25.0 & $0.1183 \pm 0.0009$ \\
\hline AA88189 & X19354 & 0.12 & -25.5 & $0.0541 \pm 0.0009$ \\
\hline AA93952 & X19472 & 0.12 & -24.8 & $0.0508 \pm 0.0006$ \\
\hline AA94165 & X19746 & 0.13 & -24.5 & $0.0628 \pm 0.0007$ \\
\hline AA93953 & X19473 & 0.16 & -25.1 & $0.0387 \pm 0.0005$ \\
\hline AA95044 & X20472 & 0.17 & -24.4 & $0.0604 \pm 0.0007$ \\
\hline AA95045 & X20473 & 0.17 & -24.5 & $0.0642 \pm 0.0007$ \\
\hline AA95046 & X20474 & 0.17 & -24.0 & $0.0577 \pm 0.0007$ \\
\hline AA93951 & X19471 & 0.20 & -24.9 & $0.0426 \pm 0.0005$ \\
\hline AA94258 & X19871 & 0.23 & -24.9 & $0.0393 \pm 0.0007$ \\
\hline AA94706 & X20311 & 0.23 & -25.0 & $0.0303 \pm 0.0005$ \\
\hline AA94166 & X19747 & 0.33 & -25.0 & $0.0260 \pm 0.0004$ \\
\hline AA94167 & X19748 & 0.39 & -24.8 & $0.0199 \pm 0.0004$ \\
\hline AA94168 & X19749 & 0.47 & -25.0 & $0.0196 \pm 0.0004$ \\
\hline \multicolumn{5}{|c|}{ Oxalic acid standards } \\
\hline Lab code & Lab \# & Mass (mg) & ${ }^{13} \mathrm{C}(\%)$ & $F$ \\
\hline AA95767 & X21086 & 0.74 & -18.8 & $1.0226 \pm 0.0042$ \\
\hline AA95768 & X21087 & 0.84 & -18.8 & $1.0314 \pm 0.0042$ \\
\hline AA95769 & X21088 & 0.87 & -18.8 & $1.0264 \pm 0.0042$ \\
\hline \multicolumn{5}{|c|}{ Tap water samples } \\
\hline AA86253 & X15251 & 0.45 & -24.0 & $0.5604 \pm 0.0035$ \\
\hline AA86254 & X15389 & 0.37 & -21.9 & $0.5603 \pm 0.0039$ \\
\hline AA86255 & X15432 & 0.34 & -21.7 & $0.5765 \pm 0.0042$ \\
\hline \multicolumn{5}{|c|}{ Groundwater (both are Barcass D24) } \\
\hline AA70681 & X4784 & 0.11 & -26.5 & $0.5213 \pm 0.0069$ \\
\hline AA86249 & X14345 & 0.33 & -23.4 & $0.5291 \pm 0.0065$ \\
\hline
\end{tabular}

${ }^{a}$ AA70681 was combusted in oxygen at $900{ }^{\circ} \mathrm{C}$ in August 2006. AA86249 is from the same well and was processed with the wet oxidation method in August 2009. 


\section{A Leonard et al.}

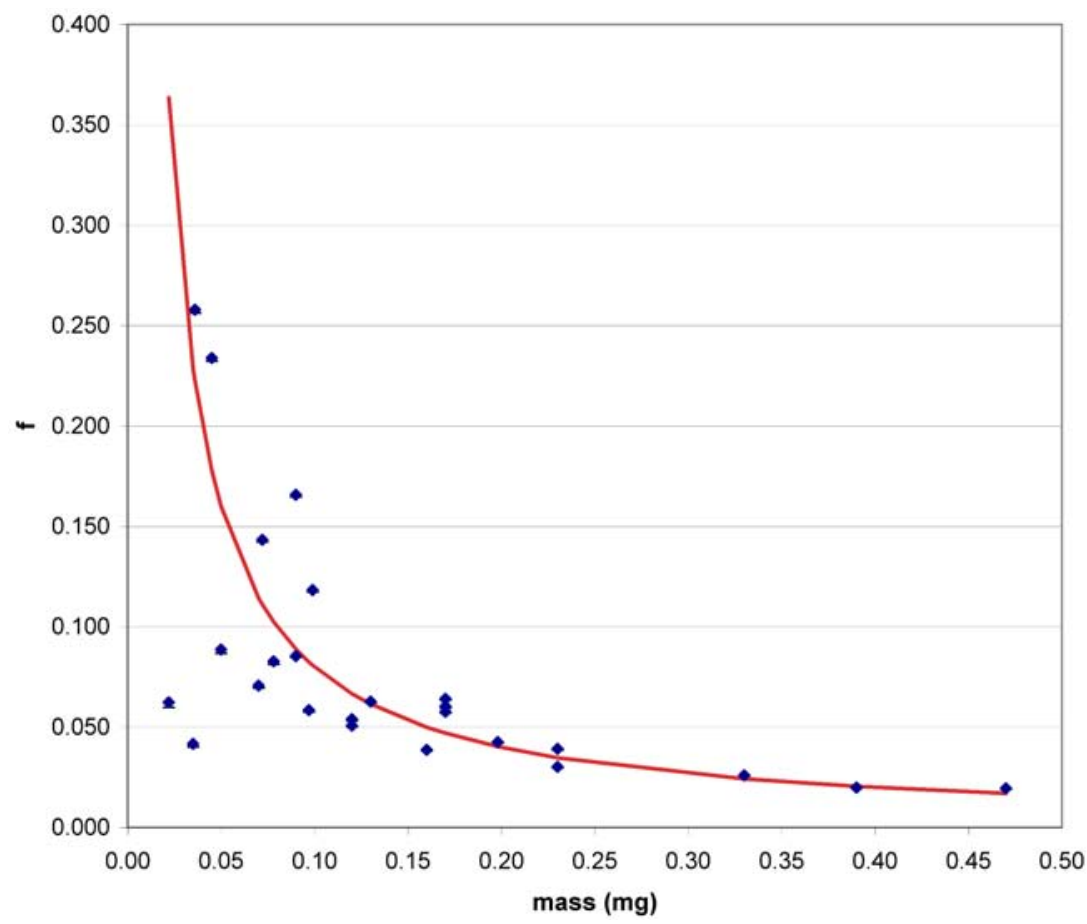

Figure 3 Blank fraction modern carbon ( $f$ ) values measured for different sample masses. The blue points are the raw data, with no blank correction or ${ }^{13} \mathrm{C}$ correction applied. The red line shows the $1 / \mathrm{m}$ dependence of the blank for samples below about $0.5 \mathrm{mg} \mathrm{C}$.

We surveyed the recent literature to compare our technique with others being used to measure ${ }^{14} \mathrm{C}$ in freshwater DOC samples by AMS. Table 2 is not an exhaustive list, but gives a fair cross-section of methods employed in different studies. It shows that there are 4 primary methods for such analyses: 1) drying and combustion (as in this study); 2) solid phase extraction (SPE) using resins of various sorts and other solid reactive materials; 3) UV oxidation; and 4) ultrafiltration. Although many of the studies listed in Table 2 discussed the overall blank for their samples, no other study specifically addressed the relationship between the sample mass and blank. Our interest in quantifying this relationship is to allow us to establish a lower limit for sample size, to correct for sample results that contain different amounts of carbon where appropriate, and to assign the uncertainty from the blank correction in a measurement, associated with a particular sample. The data presented here allows us to do that.

There are a number of differences between DOC measurements made with different techniques. As noted above, for example, the SPE and ultrafiltration methods provide information on specific DOC molecular groups, according to their molecular weights or chemical characteristics, but not total DOC. The UV method targets DOC that can be oxidized by irradiation with a UV light source. Extensive seawater analyses suggest that the UV technique captures all of the DOC (Bauer et al. 1998) and the combustion method also provides a result for total DOC. Given these differences, one should take care when comparing DOC data that have been measured using different techniques. This is true even in the case where 2 studies use the same method because DOC is operationally defined as dissolved organics that pass through a specific filter size, and the filter sizes used in the various studies quoted in Table 2 range for 0.2 to $0.8 \mu \mathrm{m}$. 
Table 2 Survey of DOC extraction methods employed in the recent literature for AMS DOC analyses of freshwater samples. Four common methods are 1) combustion following drying (freeze-drying or evaporation); 2) solid phase extraction (SPE), using resins or other solid reactants in a column; 3) UV oxidation; and 4) ultrafiltration.

\begin{tabular}{ll}
\hline $\begin{array}{l}\text { DOC sample preparation } \\
\text { method(s) }\end{array}$ & References \\
\hline Dry and combust & $\begin{array}{l}\text { Schiff et al. 1997; Palmer et al. 2001; Benner et al. 2004; Karltun et al. 2005; Neff } \\
\text { et al. 2006; Evans et al. 2007; Tipping et al. 2007, 2010; Noseck et al. 2009; Nara } \\
\text { et al. 2010a,b }\end{array}$ \\
& $\begin{array}{l}\text { Murphy et al. 1989; Hendry and Wassenaar 2003; Benner et al. 2004; Sickman et } \\
\text { al. 2010 }\end{array}$ \\
SPE & $\begin{array}{l}\text { Purdy et al. 1992; Bauer et al. 1998; Raymond and Bauer 2001; Chasar et al. 2000; } \\
\text { Raymond et al. 2004; Avery et al. 2006; Baker et al. 2011; Zigah et al. 2012 } \\
\text { UV oxidation }\end{array}$ \\
Thomas 1996; Thomas et al. 1996; Benner et al. 2004; Wang et al. 2006
\end{tabular}

\section{CONCLUSIONS}

We present a pretreatment and processing technique for isolating DOC from freshwaters for AMS ${ }^{14} \mathrm{C}$ analysis. The method is simple and inexpensive, and produces low blanks and good reproducibility. The method is modified from the direct combustion technique of Burr et al. (2001), substituting wet oxidation for high temperature combustion. The wet oxidation technique allows us to use relatively inexpensive Pyrex reaction vessels that can be used indefinitely. Although the technique is time consuming, it is less labor-intensive that the previous technique. In addition, we have devised a gas clean-up technique that is effective in removing $\mathrm{SO}_{2}$ and other contaminants from the gas produced during the wet oxidation of freshwater samples. We estimate our current DOC groundwater blank to be $f(1 \mathrm{mg})=0.0083 \pm 0.0011$, and we show that the blank increases as sample mass decreases below $500 \mu \mathrm{g}$, with a $1 / \mathrm{m}$ dependence.

\section{ACKNOWLEDGMENTS}

We wish to thank all of the students and staff at the NSF-Arizona AMS Facility for their tireless efforts in support of this work. We thank the reviewers of this paper whose comments improved the manuscript. This project was funded in part by the National Science Foundation (EAR0929458).

\section{REFERENCES}

Avery Jr GB, Willey JD, Kieber RJ. 2006. Carbon isotopic characterization of dissolved organic carbon in rainwater: terrestrial and marine influences. Atmospheric Environment 40(39):7539-45.

Baker A, Gulliver P, Ascough P, Roe J, Bridgeman J. 2011. Assessing the effect of sterilization on the radiocarbon signature of freshwater dissolved organic carbon. Radiocarbon 53(4):659-67.

Bauer JE, Druffel ERM, Williams PM, Wolgast DM, Griffin S. 1998. Temporal variability in dissolved organic carbon and radiocarbon in the eastern North $\mathrm{Pa}$ cific Ocean. Journal of Geophysical Research 103(2): 2867-81.

Benner R, Benitez-Nelson B, Kaiser K, Amon RMW. 2004. Export of young terrigenous dissolved organic carbon from rivers to the Arctic Ocean. Geophysical Research Letters 31: L05305, doi:10.1029/ $2003 G L 019251$.
Burr GS, Thomas JM, Reines D, Jeffrey D, Courtney C, Jull AJT, Lange T. 2001. Sample preparation of dissolved organic carbon in groundwater for AMS ${ }^{14} \mathrm{C}$ analysis. Radiocarbon 43(2A):183-90.

Chasar LS, Chanton JP, Glaser PH, Siegel DI, Rivers JS. 2000. Radiocarbon and stable carbon isotopic evidence for transport and transformation of dissolved organic carbon, dissolved inorganic carbon, and $\mathrm{CH}_{4}$ in a northern Minnesota peatland. Global Biogeochemical Cycles 13(4):1095-108.

Donahue DJ, Linick TW, Jull AJT. 1990. Isotope-ratio and background corrections for accelerator mass spectrometry radiocarbon measurements. Radiocarbon 32(2):135-42.

Druffel ERM, Williams PM, Bauer JE, Ertel JR. 1992. Cycling of dissolved and particulate organic matter in the open ocean. Journal of Geophysical Research 97(C10):15,639-59. 


\section{A Leonard et al.}

Evans CD, Freeman C, Cork LG, Thomas DN, Reynolds B, Billet MF, Garnett MH, Norris D. 2007. Evidence against recent climate-induced destabilisation of soil carbon from ${ }^{14} \mathrm{C}$ analysis of riverine dissolved organic matter. Geophysical Research Letters 34: LO7407, doi:10.1029/2007GL029431.

Hendry MJ, Wassenaar LI. 2005. Origin and migration of dissolved organic carbon fractions in a clay-rich aquitard: ${ }^{14} \mathrm{C}$ and ${ }^{13} \mathrm{C}$ evidence. Water Resources Research 41: W02021, doi:10.1029/2004WR003157.

Hendry MJ, Wassenaar LI. 2011. Millennial-scale diffusive migration of solutes in thick clay-rich aquitards: evidence from multiple environmental tracers. Hydrogeology Journal 19(1):259-70.

Karltun E, Harrison AF, Alriksson A, Bryant C, Garnett MH, Olsson MT. 2005. Old organic carbon in soil solution DOC after afforestation - evidence from ${ }^{14} \mathrm{C}$ analysis. Geoderma 127:188-95.

Murphy EM, Davis SN, Long A, Donahue D, Jull AJT. 1989. ${ }^{14} \mathrm{C}$ fractions of dissolved organic carbon in groundwater. Nature 337(6203):153-5.

Nara WF, Imai A, Uchida M, Matsushige K, Komatsu K, Kawasaki N, Shibata Y, Amano K, Mikami H, Hanaishi R. 2010a. High contribution of recalcitrant organic matter to DOC in Japanese oligotrophic lake revealed by ${ }^{14} \mathrm{C}$ measurements. Radiocarbon $52(2-3)$ : 1078-83.

Nara WF, Imai A, Matsushige K, Komatsu K, Kawasaki N, Shibata Y. 2010b. Radiocarbon measurements of dissolved organic carbon in sewage-treatment-plant effluent and domestic sewage. Nuclear Instruments and Methods in Physics Research B 268(7-8):1142-5.

Neff JC, Finlay JC, Zimov SA, Davydov SP, Carrasco JJ, Schuur EAG, Davydova AI. 2006. Seasonal changes in the age and structure of dissolved organic carbon in Siberian rivers and streams. Geophysical Research Letters 33: L23401, doi:10.1029/2006GL028222.

Noseck U, Rozanski K, Dulinski M, Havlov V, Sracek O, Brasser T, Hercik M, Buckau G. 2009. Carbon chemistry and groundwater dynamics at natural analogue site Ruprechtov, Czech Republic: insights from environmental isotopes. Applied Geochemistry 24(9): 1765-76.

Palmer SM, Hope D, Billett MF, Dawson JJC, Bryant CL. 2001. Sources of organic and inorganic carbon in a headwater stream: evidence from carbon isotope studies. Biogeochemistry 52(3):321-38.

Purdy CB, Burr GS, Rubin M, Helz GR, Mignerey AC. 1992. Dissolved organic and inorganic ${ }^{14} \mathrm{C}$ concentrations and ages for coastal plain aquifers in southern Maryland. Radiocarbon 34(3):654-63.

Raymond PA, Bauer JE. 2001. Riverine export of aged terrestrial organic matter to the North Atlantic. Nature 409(6819):497-500.

Raymond PA, Bauer JE, Caraco NF, Cole JJ, Longworth B, Petsch ST. 2004. Controls on the variability of organic matter and dissolved inorganic carbon ages in northeast US rivers. Marine Chemistry 92(1-4):35366.

Schiff SL, Aravena R, Trumbore SE, Hinton MJ, Elgood R, Dillon PJ. 1997. Export of DOC from forested catchments on the Precambrian Shield of central Ontario: clues from ${ }^{13} \mathrm{C}$ and ${ }^{14} \mathrm{C}$. Biogeochemistry 36(1): 43-65.

Sickman JO, DiGiorgio CL, Davisson ML, Lucero DM, Bergamaschi B. 2010. Identifying sources of dissolved organic carbon in agriculturally dominated rivers using radiocarbon age dating: Sacramento-San Joaquin River basin, California. Biogeochemistry 99(1-3):79-96.

Thomas JM. 1996. Geochemical and isotopic interpretation of groundwater flow, geochemical processes, and age dating of groundwater in the carbonate-rock aquifers of the southern Basin and Range $[\mathrm{PhD}$ dissertation]. University of Nevada, Reno. 135 p.

Thomas JM, Welch AH, Dettinger MD. 1996. Geochemistry and isotope hydrology of representative aquifers in the Great Basin region of Nevada, Utah, and adjacent states. US Geological Survey Professional Paper 1409-C. 100 p.

Tipping E, Smith EJ, Bryant CL, Adamson JK. 2007. The organic carbon dynamics of a moorland catchment in N.W. England. Biogeochemistry 84(2):171-89.

Tipping E, Billett MF, Bryant CL, Buckingham S, Thacker SA. 2010. Sources and ages of dissolved organic matter in peatland streams: evidence from chemistry mixture modelling and radiocarbon data. Biogeochemistry 100(1-3):121-37.

Wang X-C, Callahan J, Chen RF. 2007. Variability in radiocarbon ages of biochemical compound classes of high molecular weight dissolved organic matter in estuaries. Estuarine Coastal and Shelf Science 68(1-2): 188-94.

Wassenaar LI, Hendry MJ, Aravena R, Fritz P. 1990. Organic carbon isotope geochemistry of clayey deposits and their associated porewaters, southern Alberta. Journal of Hydrology 120(1-4):251-70.

Williams PM, Druffel ERM. 1987. Radiocarbon in dissolved organic matter in the central North Pacific Ocean. Nature 330(6145):246-8.

Zigah PK, Minor EC, Werne JP. 2012. Radiocarbon and stable-isotope geochemistry of organic and inorganic carbon in Lake Superior. Global Biogeochemical Cycles 26: GB1023, doi:10.1029/2011GB004132. 